\title{
Characterizing advanced Parkinson's disease: OBSERVE-PD observational study results of 2615 patients
}

\author{
Alfonso Fasano ${ }^{1,2^{*}}$, Victor S. C. Fung ${ }^{3,4}$, Leonardo Lopiano ${ }^{5}$, Bulent Elibol ${ }^{6}$, Irina G. Smolentseva ${ }^{7}$, Klaus Seppi ${ }^{8}$, \\ Annamária Takáts ${ }^{9}$, Koray Onuk ${ }^{10}$, Juan Carlos Parra ${ }^{10}$, Lars Bergmann ${ }^{10}$, Kavita Sail ${ }^{10}$, Yash Jalundhwala ${ }^{10}$ and \\ Zvezdan Pirtosek ${ }^{11}$
}

\begin{abstract}
Background: There are currently no standard diagnostic criteria for characterizing advanced Parkinson's disease (APD) in clinical practice, a critical component in determining ongoing clinical care and therapeutic strategies, including transitioning to device-aided treatment. The goal of this analysis was to determine the proportion of APD vs. non-advanced PD (non-APD) patients attending specialist PD clinics and to demonstrate the clinical burden of APD.

Methods: OBSERVE-PD, a cross-sectional, international, observational study, was conducted with 2615 PD patients at 128 movement disorder centers in 18 countries. Motor and non-motor symptoms, activities of daily living, and quality-of-life end points were assessed. The correlation between physician's global assessment of advanced PD and the advanced PD criteria from a consensus of an international group of experts (Delphi criteria for APD) were evaluated.

Results: According to physician's judgment, 51\% of patients were considered to have APD. There was a moderate correlation between physician's judgment and Delphi criteria for APD ( $K=0.430 ; 95 \% \mathrm{Cl} 0.406-0.473)$. Activities of daily living, motor symptom severity, dyskinesia duration/disability, "Off" time duration, non-motor symptoms, and quality-of-life scores were worse among APD vs. non-APD patients ( $p<0.0001$ for all). APD patients (assessed by physicians) had higher disease burden by motor and non-motor symptoms compared with non-APD patients and a negative impact on activities of daily living and quality of life.
\end{abstract}

Conclusions: These findings aid in identifying standard APD classification parameters for use in practicing physicians. Improvements in identification of APD patients may be particularly relevant for optimizing treatment strategies including transitioning to device-aided treatment.

Keywords: Advanced Parkinson's disease, Device-aided treatment, Quality of life

\section{Background}

Patient progression to advanced Parkinson's disease (APD) has conventionally not been well-defined. The worsening of cardinal features of PD (e.g. tremor,

\footnotetext{
* Correspondence: alfonso.fasano@uhn.ca

'Edmond J. Safra Program in Parkinson's Disease and Morton and Gloria Shulman Movement Disorders Clinic, Toronto Western Hospital and Division of Neurology, UHN, Division of Neurology, University of Toronto, 399 Bathurst St, 7McL412, Toronto, ON M5T 2S8, Canada

${ }^{2}$ Krembil Research Institute, 399 Bathurst St, Toronto, Ontario M5T 2S8,

Canada

Full list of author information is available at the end of the article
}

rigidity, akinesia, and postural instability) are inevitable as disease progression occurs. The onset of motor fluctuations and/or levodopa-induced dyskinesia is commonly accepted as a marker of progression of the disease; however, determining the point at which a patient is classified as having APD is not distinct and imposes continued challenges, particularly when determining appropriate therapeutic recommendations for optimization of patient outcomes. Although commonly used in routine clinical practice to identify the clinical stages of PD, the Hoehn and Yahr scale has limitations

(c) The Author(s). 2019 Open Access This article is distributed under the terms of the Creative Commons Attribution 4.0 International License (http://creativecommons.org/licenses/by/4.0/), which permits unrestricted use, distribution, and 
[1], including limited capture of motor and non-motor symptoms (NMS) and inability to measure quality of life (QoL) [2-4].

As PD symptoms become increasingly refractory to oral treatments, device-aided treatment (DAT) (i.e. treatment that extends beyond oral medications) such as stereotactic surgery for deep brain stimulation (DBS) and infusion therapies-namely continuous subcutaneous apomorphine infusion (CSAI) or levodopa-carbidopa intestinal gel (LCIG) - may be considered [5, 6]. Switching from oral PD treatment to invasive therapeutics is typically determined in movement disorder centers/ clinics that provide comprehensive treatment by a multidisciplinary expert group. Even within these clinics there are variable reports on percentages of APD patients [7-9], highlighting potential discrepancies between identification, categorization, and total number of APD patients. Differences in practice patterns between general neurologists and movement disorder specialists may contribute to these discrepancies. Consistent identification and categorization of APD patients in movement disorder clinics is critical for these centers to provide sufficient resources for patient education for APD symptom management and key information on DAT. Standardized criteria may also have an educational effect for the nonspecialized neurologist who can then monitor patients for specific symptoms and refer patients in real time when treatment optimization is still possible.

The OBSERVE-PD (OBSERVational, cross-sEctional PD) study was designed to determine the proportion of patients with APD in movement disorder clinics in different regions. Predefined objectives included the characterization of clinical and non-clinical features based on physician's judgment and newly developed Delphi criteria for APD, as well as a comparison of the two assessments' determination of APD [10]. Additionally, characteristics of APD patients were examined based on DAT-eligibility.

\section{Methods}

\section{Study setting and patient selection}

Movement disorder clinics were selected based on DAT availability (i.e. LCIG, CSAI, or DBS) offered by an expert/specialist team. This observation study included PD patients who were attending a routine clinical visit or were inpatients at participating movement disorder clinics. Consecutive patients were asked for their interest in participation and were enrolled in the study at each site to avoid selection bias. To be included in the study, patients had to be at least 18 years old with a clinical diagnosis of PD. Patients had to sign an authorization form to disclose personal health information and an informed consent form and be fluent in the language of the provided patient questionnaire. Patients were excluded if in the "Off" stage at the time of visit, if there was significant uncertainty around the PD diagnosis (i.e. symptoms suggesting non-idiopathic PD such as early falls or early autonomic disturbances, lack of levodopa responsiveness, supranuclear gaze disturbances, history of repeated strokes with stepwise progression of parkinsonism), or if patients were participating in a concurrent clinical study. The study was approved by local ethics committees and performed according to the International Conference on Harmonization and Good Clinical Practice requirements, in accord with the principles of the Declaration of Helsinki.

\section{Study assessments}

Following signed consent, data were collected from each patient at a single study visit. Patient records provided demographic information (age, sex, race, patient residence, and caregiver support), cognitive function (assessed in the case report form in a general manner, not using a scale), PD-related information (date of diagnosis, referral history, and disease stage based on physician's judgment), PD treatment information (PD treatment history, patient qualification/eligibility for invasive therapy according to physician's judgment, current PD treatment [s] and physician's assessment of response to current treatment), and comorbidities. Patient qualification/eligibility for DAT was not mandated by certain eligibility criteria set forth by the study and was instead dictated by the movement disorder specialist's judgment for potential patient candidacy for DAT. Motor symptoms assessed during the study visit included Unified Parkinson's Disease Rating Scale (UPDRS) in "On" stage (includes Part II [activities of daily living, ADL], Part III [motor complications], and Part IV [items 32, 33, 34, and 39; complications of therapy]), and UPDRS Part V (modified Hoehn and Yahr scale staging). Non-motor symptoms were assessed using the Non-motor Symptom Scale (NMSS), and QoL was assessed using the 8-item Parkinson's Disease Quality of Life Questionnaire (PDQ-8).

\section{Delphi criteria for APD}

Delphi criteria for APD were developed as a staging tool to help clinicians identify patients with APD using consistent characterization, which therefore will assist in optimizing patient treatment care (e.g. DAT eligibility) [10]. The Delphi versus physician judgment comparison was a pre-defined end point. Patients were first assessed by the investigator using their own physician's judgment and then assessed using the Delphi criteria. Independent assessments were not possible as the outcomes were determined by the same investigator. In this study, patients were assessed by movement disorder specialists using 11 indicators (Table 1) of suspected APD identified through 
Table 1 Delphi criteria for APD [10]

\begin{tabular}{|c|c|}
\hline Delphi consensus criteria questions & Patient has \\
\hline $\begin{array}{l}\text { 1. Troublesome motor fluctuations, } \\
\text { severity level }\end{array}$ & Moderate or severe \\
\hline 2. "Off" time, hours/waking day & $\geq 2$ or $<2$ \\
\hline $\begin{array}{l}\text { 3. Nighttime sleep disturbances, } \\
\text { severity level }\end{array}$ & Moderate or severe \\
\hline $\begin{array}{l}\text { 4. Troublesome dyskinesia, hours/ } \\
\text { waking day }\end{array}$ & $2-3$ or $>3$ \\
\hline 5. Non-motor fluctuations present & Yes \\
\hline 6. "Off" time at least every $3 \mathrm{~h}$ & Yes \\
\hline 7. $\geq 5$ times daily oral levodopa dosing & Yes \\
\hline $\begin{array}{l}\text { 8. Activities of daily living limitation, } \\
\text { severity level }\end{array}$ & Moderate or severe \\
\hline 9. Falling, frequency & $\begin{array}{l}\text { Most of the time or all } \\
\text { the time }\end{array}$ \\
\hline 10. Dementia, severity level & Moderate or severe \\
\hline 11. Psychosis, severity level & Moderate or Severe \\
\hline
\end{tabular}

a Delphi consensus methodology by an international movement disorder specialist's expert group. Patients having any of the indicators were identified as having APD [10]. As APD was determined by individual physician judgment, no comparison to other scales was conducted. Patients with ongoing DAT were not assessed using the Delphi criteria as the comparison was considered invalid as they would usually experience better clinical outcomes.

\section{Safety}

This observational study was not designed to identify or quantify safety aspects of any therapy. Any product-related events were reported in accord with local laws and regulations to the relevant regulatory authority and/or drug marketing authorization holder. Patient data were documented on data report forms. Representatives at each center were asked to complete a site information form.

\section{Statistical analysis}

Statistical analyses were performed using the SAS ${ }^{\oplus}$ package, version 9.2 (SAS Institute, Cary, NC). Data were summarized using descriptive statistics. The primary end point was the proportion of PD patients who had APD according to physician judgment. A secondary end point compared physicians' judgment with the Delphi criteria for APD. A multivariable logistic regression analysis was applied with physicians' assessments of APD as target variable and 32 potential prognostic factors including all Delphi criteria for APD, UPDRS II to V, UPDRS IV item 32, UPDRS IV item 33, UPDRS IV item 34, UPDRS item 39, NMSS score, PDQ-8, time since diagnosis, current invasive PD treatment, gender, race, education, motor fluctuations, caregiver support, comorbidities, geographic region, occupation, and type of residence. The correlation between the Delphi criteria for APD and physicians' assessments of APD were confirmed with an additional sensitivity analysis by excluding ongoing DAT patients to eliminate any potential masking effect of the invasive treatment. Two-sided 95\% CIs were provided for comparative end points; CIs and $p$ values (two-sample $t$ test) were calculated for differences between APD and non-advanced PD (non-APD) patients.

A post hoc analysis assessed baseline demographics and disease characteristics of APD patients who were assessed as eligible or ineligible for DAT by the treating physician. Patient characteristics were analyzed using descriptive statistics. An analysis of variance compared disease characteristics of patients eligible for DAT (ongoing DAT versus planned DAT versus no DAT) and patients ineligible for DAT with $t$ tests for pairwise comparisons between each group for selected scale scores.

\section{Results}

\section{Comparisons between APD and non-APD patients}

This study evaluated 2615 PD patients from 128 movement disorder clinics in 18 countries. According to physician's assessments, $51.3 \%(n=1342)$ of recruited PD patients had APD; this proportion varied regionally (range: 24 to $82 \%$; Table 2). There were no differences between APD and non-APD patient percentages regarding age, sex, and living situation (Table 3). Notable differences were observed in caregiver support status, which was needed by most APD patients (69.1\%), whereas only $25.8 \%$ of non-APD patients had caregiver support. Most patients (APD and non-APD) were on oral levodopa/carbidopa or oral dopamine agonists at the time of the study (Additional file 1: Table S1).

Patients with physician-assessed APD had a greater disease burden than non-APD (Fig. 1). Mean scores for ADL, motor symptom severity, dyskinesia duration and disability, average duration of "Off" time, NMS, and QoL were all significantly worse among APD patients than non-APD patients $(p<0.0001$ for all). Most (87\%) APD patients experienced motor fluctuations $(94 \%$ of DAT-eligible patients and $74 \%$ of DAT-ineligible patients).

\section{Delphi criteria for APD}

There was a moderate correlation between physician's judgment of APD and classification based on all indicators of APD identified by the Delphi criteria $(\mathrm{K}=0.441$; 95\% CI, 0.408-0.473); there was also a moderate correlation between individual items from the Delphi criteria for APD and physician's judgment (Table 4). A sensitivity analysis, which excluded patients with ongoing DAT, confirmed the moderate correlation 
Table 2 APD and non-APD by country based on investigator's judgment

\begin{tabular}{lll}
\hline Country, n (\%) & APD & Non-APD \\
\hline Australia & $61(61)$ & $39(39)$ \\
Austria & $73(61)$ & $47(39)$ \\
Belgium & $77(46)$ & $90(54)$ \\
Canada & $78(32)$ & $164(68)$ \\
Croatia & $32(58)$ & $23(42)$ \\
Czech Republic & $60(82)$ & $13(18)$ \\
Germany & $122(69)$ & $55(31)$ \\
Greece & $65(38)$ & $105(62)$ \\
Hungary & $50(50)$ & $50(50)$ \\
Ireland & $29(24)$ & $90(76)$ \\
Israel & $70(58)$ & $50(42)$ \\
Italy & $60(43)$ & $80(57)$ \\
Romania & $95(59)$ & $66(41)$ \\
Russia & $106(42)$ & $144(58)$ \\
Slovakia & $102(80)$ & $26(20)$ \\
Slovenia & $45(46)$ & $54(54)$ \\
Switzerland & $93(69)$ & $41(31)$ \\
Turkey & $124(48)$ & $136(52)$ \\
\hline ADP advance Pakn) &
\end{tabular}

$A D P$ advanced Parkinson's disease, non- $A P D$ non-advanced Parkinson's disease
( $\mathrm{K}=0.430$; 95\% CI, 0.397-0.464; Additional file 1: Table S2). Correlations with physician's judgment were significant for the Delphi criteria of $\geq 5$ times daily oral levodopa dosing $(p<0.0001)$ and level of limitation of activities of daily living $(p=0.0022)$. Physician's judgment of APD also correlated with UPDRS II score $(p<0.05)$, Hoehn and Yahr score $(p<0.0001)$, NMSS score $(p<0.05)$, time since diagnosis $(p<0.0001)$, current invasive PD treatment $(p<0.0001)$, motor fluctuations $(p<0.0001)$, existence of caregiver support $(p<0.001)$, and type of residence $(p<0.05)$ (Additional file 1: Table S3).

\section{DAT eligibility according to physician's judgment}

Of 1342 APD patients, $882(66 \%)$ patients were eligible for DAT and 34\% $(n=460)$ were ineligible. Of 1272 non-APD patients, $127(10 \%)$ patients were eligible for DAT. Of 882 APD DAT-eligible patients, 384 (43.6\%) had ongoing DAT, 164 (18.6\%) had decided to initiate DAT during the study visit, and 332 (37.7\%) had no DAT planned (data were unavailable for two subjects). Patients deemed eligible but who had no DAT planned listed the need for more time to decide (39\%) and/or patient refusal (25\%) as primary reasons for not using DAT (Table 5).

A comparison of baseline characteristics by DAT eligibility is shown in Table 6. Of 384 patients currently on DAT, $57 \%$ were using DBS, 39\% were using LCIG, and

Table 3 Characteristics of ADP and non-ADP based on physician's judgment

\begin{tabular}{|c|c|c|c|c|}
\hline \multirow[b]{2}{*}{ Characteristics } & \multicolumn{2}{|l|}{ APD, $N=1342$} & \multicolumn{2}{|c|}{ Non-APD, $N=1273$} \\
\hline & n/N (\%) & Mean (SD) & $\mathrm{n} / \mathrm{N}(\%)$ & Mean (SD) \\
\hline Age, years & & $\begin{array}{l}67.6(9.4) \\
n=1338\end{array}$ & & $\begin{array}{l}66.4(10.3) \\
n=1272\end{array}$ \\
\hline Sex, male & $817 / 1342(61)$ & & 734/1273 (58) & \\
\hline Living at home & $1304 / 1342(97)$ & & $1264 / 1273(99)$ & \\
\hline Required caregiver support, yes & 917/1327 (69) & & $328 / 1270(26)$ & \\
\hline Time since diagnosis, years & & $\begin{array}{l}11.0(5.8) \\
n=1304\end{array}$ & & $\begin{array}{l}4.3(3.7) \\
n=1249\end{array}$ \\
\hline Motor fluctuations present, yes & $1167 / 1342(87)$ & & 295/1273 (23) & \\
\hline Duration of motor fluctuations, years & & $\begin{array}{l}4.9(3.9) \\
n=1151\end{array}$ & & $\begin{array}{l}2.3(2.1) \\
n=272\end{array}$ \\
\hline UPDRS V: Modified Hoehn \& Yahr score & & $\begin{array}{l}2.9(0.8)^{\mathrm{a}} \\
N=1342\end{array}$ & & $\begin{array}{l}2.0(0.6)^{\mathrm{a}} \\
n=1272\end{array}$ \\
\hline Eligible for invasive treatment options, yes & $882 / 1342(66)$ & & $127 / 1272(10)$ & \\
\hline \multicolumn{5}{|c|}{ Status of invasive treatment for eligible patients } \\
\hline Ongoing & 384/882 (44) & & 15/127 (12) & \\
\hline Decided at visit to start & 164/882 (19) & & 17/127 (13) & \\
\hline No & 332/882 (38) & & $91 / 127(72)$ & \\
\hline Missing & 2/882 (0.2) & & 4/127 (3.1) & \\
\hline
\end{tabular}

${ }^{a}$ The UPDRS was measured in the "On" state. Statistical significance based on a $t$ test comparison between APD and non-APD patients are indicated at the $p<$ 0.0001 . All proportions except for the invasive treatment status included patients with no missing data. APD advanced Parkinson's disease, non-APD non-advanced Parkinson's disease, PD Parkinson's disease, SD standard deviation, UPDRS Unified Parkinson's Disease Rating Scale 

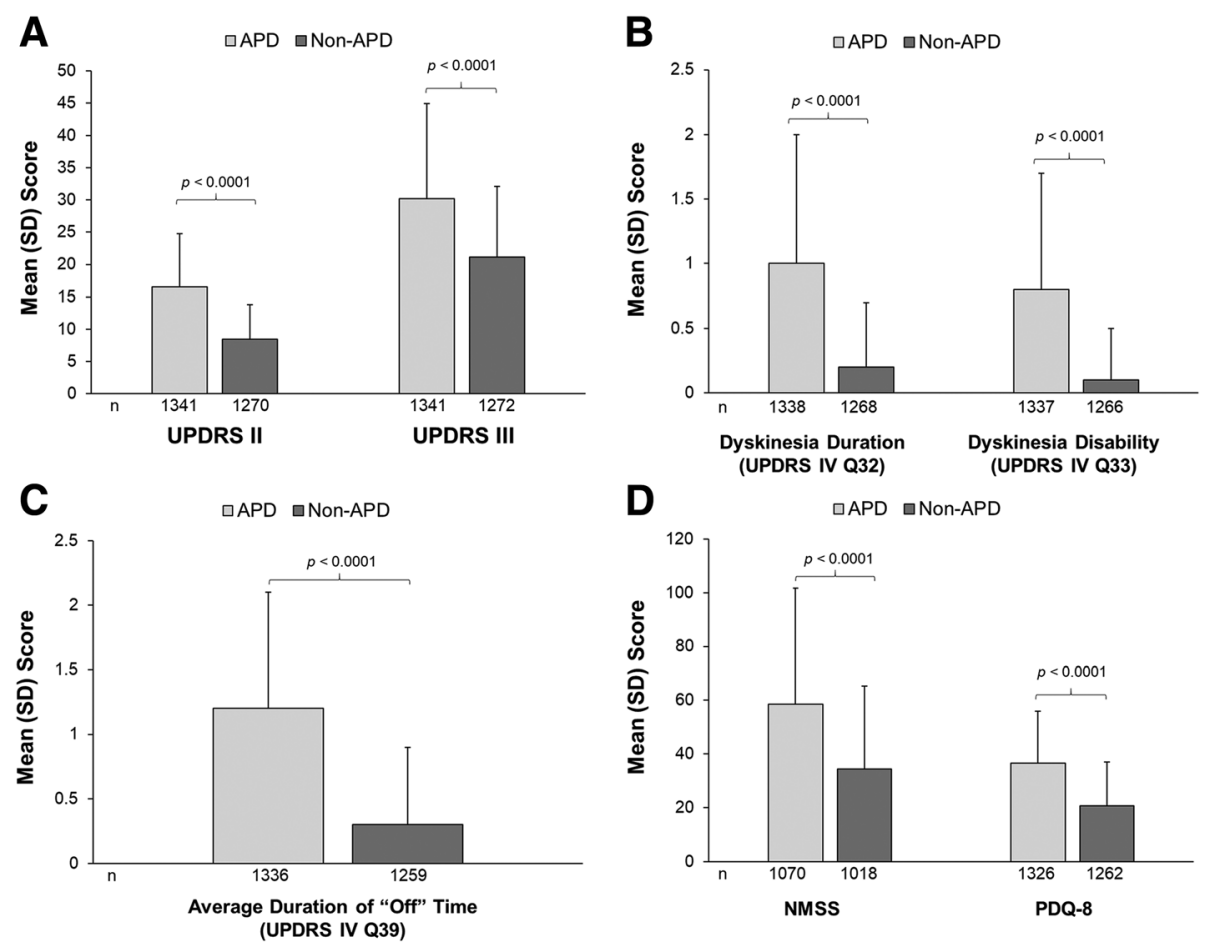

Fig. 1 Clinical PD assessments in APD versus non-APD patients. a Activities of daily living (UPDRS II) and motor symptom severity (UPDRS III), b dyskinesia duration and disability (UPDRS Part IV Q32 and Q33), c average duration of "Off" time (UPDRS Part IV Q39), and (d) NMS burden and quality of life (PDQ-8). Error bars indicate the standard deviation. $p$ values from a paired $t$ test indicate statistical significance. APD $=A d v a n c e d$ Parkinson's disease; non-APD = Non-advanced Parkinson's disease; NMSS = Non-motor Symptom Scale; PDQ-8 = Parkinson's disease 8-item questionnaire; SD = Standard deviation; UPDRS = Unified Parkinson's Disease Rating Scale

$8 \%$ were receiving CSAI (patients were not limited to only one DAT). Mean (SD) duration of DBS treatment, LCIG therapy, and CSAI was 39.9 (41.5) months, 20.3 (20.1) months, and 22.6 (27.6) months, respectively. The number of current PD treatments per APD patient ranged from one to six (one, 19.7\%; two, 33.6\%; three, $28.5 \%$; four, $12.0 \%$; five, $3.8 \%$; and six, $0.3 \%$ ).

Patients with APD currently receiving DAT had significantly lower impairment in ADL compared with APD patients who had planned DAT $(p=0.0389)$ and compared with APD patients who had no DAT planned $(p=0.0048)$ (Fig. 2a). Patients who were currently receiving DAT had significantly lower impairment in motor symptoms compared with patients who had planned DAT $(p=0.0002)$ and those who had no DAT planned $(p<0.0001)$; motor symptom severity was also significantly lower in the combined DAT-eligible group compared with DAT-ineligible patients ( $p=0.0047)$.

Patients currently receiving DAT had significantly lower scores for dyskinesia duration than those with planned DAT $(p=0.0140)$. Dyskinesia disability was significantly lower for patients with ongoing DAT compared with patients who had DAT planned $(p<0.0001)$ and with patients who had no DAT planned ( $p=0.0067)$ (Fig. 2b). Average duration of "Off" time was significantly lower for patients receiving ongoing DAT compared with patients who had planned DAT $(p<0.0001)$, and with patients who had no DAT planned ( $p<0.0001)$ (Fig. 2c). Patients currently receiving DAT had significantly lower NMSS total scores than patients with no DAT planned $(p=0.0171)$ (Fig. 2d).

Dyskinesia duration and disability scores and "Off" time were significantly lower in DAT-ineligible patients than in DAT-eligible patients who are not yet treated ( $p<0.0001$ for all). QoL was significantly better in DAT-ineligible patients than in the combined DATeligible patient group $(p=0.0064)$.

\section{Discussion}

The progressive nature of PD means that categorical sorting of patients into distinct disease stages might help to ensure implementation of best practices and effective treatment strategies. As PD progresses, oral pharmacotherapeutic strategies may not be as efficient in some patients, and more invasive DAT (e.g. continuous-infusion therapies [CSAI and LCIG] and DBS) need to be initiated to manage symptoms and maintain QoL [5]. Clinical indicators for categorizing APD are ambiguous and subjective, presenting unmet needs for enhanced descriptions and guidelines 
Table 4 Correlations between physician's judgment of APD and individual Delphi criteria for APD

\begin{tabular}{|c|c|c|c|c|c|}
\hline \multirow{3}{*}{$\begin{array}{l}\text { Prognostic parameter } \\
\text { Troublesome motor fluctuations } \\
\text { (severity level, moderate/severe versus mild) }\end{array}$} & \multirow{3}{*}{$\begin{array}{l}\text { Regression coefficient } \\
0.1122\end{array}$} & \multicolumn{4}{|l|}{ Odds ratio } \\
\hline & & \multirow{2}{*}{$\begin{array}{l}\text { Adjusted estimate } \\
1.119\end{array}$} & \multicolumn{2}{|c|}{ 95\% Wald Cl } & \multirow{2}{*}{$\frac{p \text { value }}{0.5909}$} \\
\hline & & & 0.743 & 1.684 & \\
\hline $\begin{array}{l}\text { "Off" time } \\
\text { (hours/waking day, } \geq 2 \mathrm{~h} \text { versus }<2 \mathrm{~h}\end{array}$ & 0.0190 & 1.019 & 0.691 & 1.503 & 0.9235 \\
\hline $\begin{array}{l}\text { Nighttime sleep disturbances } \\
\text { (severity level, moderate/severe versus mild) }\end{array}$ & 0.0167 & 1.017 & 0.744 & 1.389 & 0.9166 \\
\hline $\begin{array}{l}\text { Troublesome dyskinesia } \\
\text { (hours/waking day, } \geq 2 \mathrm{~h} \text { versus }<2 \mathrm{~h} \text { ) }\end{array}$ & 0.3610 & 1.435 & 0.827 & 2.490 & 0.1993 \\
\hline $\begin{array}{l}\text { Non-motor fluctuations present } \\
\text { (yes versus no) }\end{array}$ & 0.1763 & 1.193 & 0.893 & 1.593 & 0.2322 \\
\hline $\begin{array}{l}\text { "Off" time at least every } 3 \mathrm{~h} \\
\text { (yes versus no) }\end{array}$ & 0.3944 & 1.483 & 0.978 & 2.251 & 0.0638 \\
\hline $\begin{array}{l}\geq 5 \text { times daily oral levodopa dosing } \\
\text { (yes versus no) }\end{array}$ & 0.7417 & 2.100 & 1.544 & 2.854 & $<0.0001$ \\
\hline $\begin{array}{l}\text { Activities of daily living limitation } \\
\text { (severity level, moderate/severe versus mild) }\end{array}$ & 0.5389 & 1.714 & 1.213 & 2.422 & $0.0022^{a}$ \\
\hline $\begin{array}{l}\text { Falling } \\
\text { (frequency, most/all the time versus some of the time) }\end{array}$ & 0.0432 & 1.044 & 0.397 & 2.744 & 0.9302 \\
\hline $\begin{array}{l}\text { Dementia } \\
\text { (severity level, moderate/severe versus mild) }\end{array}$ & -0.4134 & 0.661 & 0.399 & 1.097 & 0.1093 \\
\hline $\begin{array}{l}\text { Psychosis } \\
\text { (severity level, moderate/severe versus mild) }\end{array}$ & 0.5745 & 1.776 & 0.846 & 3.731 & 0.1291 \\
\hline
\end{tabular}

${ }^{a}$ Correlations with physician's judgment were significant for the Delphi criteria $\geq 5$ times daily oral levodopa dosing ( $\left.p<0.0001\right)$ and activities of daily living limitation $(p=0.0022)$. APD advanced Parkinson's disease, $\mathrm{Cl}$ confidence interval

relating to the staging of APD and precise timeframes for DAT implementation. Current classification methods based on motor symptom trajectory do not provide a comprehensive patient profile to accurately characterize the multidimensional features of motor and non-motor manifestations accompanying APD.

Table 5 Reasons patients with APD were not using DAT

\begin{tabular}{ll}
\hline Reason $^{\text {a }}$ & Patients, $\mathrm{n}(\%), n=332$ \\
\hline Patient characteristic reasons $^{\text {Cognitive-related issues }}$ & $27(8)$ \\
Psychiatric-related issues & $23(7)$ \\
Comorbidities & $20(6)$ \\
Age & $12(4)$ \\
Lack of caregiver/family support & $11(3)$ \\
Motor function-related issues & $6(2)$ \\
Reasons related to patient decision & \\
Patient needs more time to decide & $129(39)$ \\
Patient refusal & $82(25)$ \\
Other reasons & 0 \\
Cost/reimbursement & $45(14)$ \\
Other reasons &
\end{tabular}

${ }^{a}$ Multiple entries for each patient were possible. A total of 23 patients who gave reasons related to patient decisions and had physician-based patient characteristic reasons were excluded

$A P D$ advanced Parkinson's disease, DAT device-aided treatment
The current study aimed to determine the proportion of PD patients identified as having APD according to physician's assessment, to compare the clinical features of APD and non-APD patients, and to compare newly developed Delphi criteria for APD with physician's judgment. The current study is the first report to include international data on the proportion of APD, clinical features, evaluation of physician's judgment, use of the Delphi criteria in routine clinical practice, gaps in patient identification, and standard patient scores.

The key limitations of the regularly used Hoehn \& Yahr staging is the neglect of non-motor symptoms and levodopa-induced complications (e.g. motor fluctuations, dyskinesia) which strongly contribute to impaired QoL in APD [11]. We found a moderate correlation between physician's judgment and Delphi criteria for APD, indicating some consensus already. Approximately half of the PD patients at movement disorder clinics were classified by the physician as APD, although the range varied considerably in certain countries. These variations highlight the inconsistencies among health systems, movement disorders clinics, and physicians in differing regions to categorize APD and may be based on different intercultural disease perceptions and treatment availabilities. The high proportion of APD classification (i.e. $51 \%$ ) by clinician judgment is not meant to 
Table 6 Baseline characteristics of DAT-eligible and DAT-ineligible patients with APD

\begin{tabular}{|c|c|c|c|c|}
\hline \multirow[t]{2}{*}{ Characteristics } & \multicolumn{2}{|c|}{ DAT-eligible, $n=882^{\mathrm{a}}$} & \multirow[b]{2}{*}{$\begin{array}{l}\text { Not planned } \\
n=332\end{array}$} & \multirow[b]{2}{*}{$\begin{array}{l}\text { DAT-ineligible } \\
n=460\end{array}$} \\
\hline & $\begin{array}{l}\text { Ongoing DAT } \\
n=384\end{array}$ & $\begin{array}{l}\text { Planned DAT } \\
n=164\end{array}$ & & \\
\hline \multicolumn{5}{|l|}{ Demographics } \\
\hline Age, years, mean (SD) & $\begin{array}{l}65.1(8.7) \\
n=383\end{array}$ & $\begin{array}{l}64.3(9.0) \\
n=163\end{array}$ & $\begin{array}{l}67.8(9.6) \\
n=330\end{array}$ & $70.6(9.1)$ \\
\hline Sex, male, n (\%) & $239(62)$ & $103(63)$ & $200(60)$ & $274(60)$ \\
\hline Caregiver support, n (\%) & $\begin{array}{l}278(73) \\
n=380\end{array}$ & $\begin{array}{l}109(67) \\
n=162\end{array}$ & $\begin{array}{l}242(74) \\
n=328\end{array}$ & $286(63)$ \\
\hline \multicolumn{5}{|l|}{ Medical history } \\
\hline PD duration, years, mean (SD) & $\begin{array}{l}14.2(5.6) \\
n=372\end{array}$ & $\begin{array}{l}10.1(4.7) \\
n=160\end{array}$ & $\begin{array}{l}11.1(5.0 \\
n=322\end{array}$ & $\begin{array}{l}8.6(5.5) \\
n=449\end{array}$ \\
\hline Motor fluctuations, n (\%) & $353(92)$ & $154(94)$ & $320(96)$ & $338(74)$ \\
\hline Motor fluctuation duration years, mean (SD) & $\begin{array}{l}7.2(4.3) \\
n=351\end{array}$ & $\begin{array}{l}4.2(2.8) \\
n=152\end{array}$ & $\begin{array}{l}4.4(3.5) \\
n=312\end{array}$ & $\begin{array}{l}3.3(2.9) \\
n=334\end{array}$ \\
\hline Comorbidity, n (\%) & $327(85)$ & $135(82)$ & $301(91)$ & $431(94)$ \\
\hline Time since referral to center, years, mean (SD) & $\begin{array}{l}5.2(5.5) \\
n=305\end{array}$ & $\begin{array}{l}2.7(3.7) \\
n=119\end{array}$ & $\begin{array}{l}4.7(4.8) \\
n=231\end{array}$ & $\begin{array}{l}4.0(4.6) \\
n=340\end{array}$ \\
\hline
\end{tabular}

atwo patients had missing data

$A P D$ advanced Parkinson's disease, DAT device-aided treatment, $P D$ Parkinson's disease, SD standard deviation
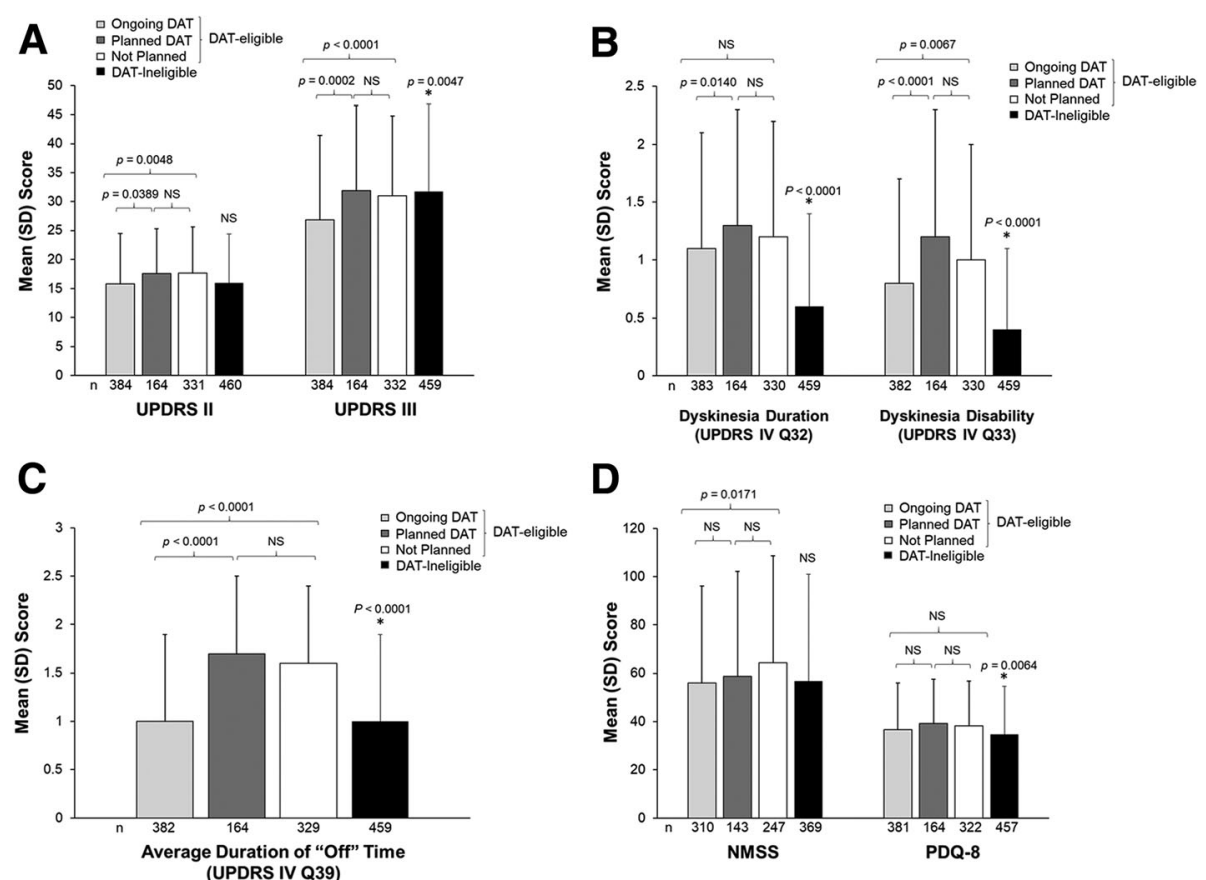

Fig. 2 Clinical PD assessments based on DAT eligibility and status. Comparisons between DAT groups (ongoing, planned, not planned, and ineligible) are shown for (a) activities of daily living (UPDRS II) and motor symptom severity (UPDRS III), $\mathbf{b}$ dyskinesia duration and disability (UPDRS Part IV Q32 and Q33), c average duration of "Off" time (UPDRS Part IV Q39), and (d) NMS burden and QoL (PDQ-8). Error bars indicate the standard deviation. $p$ values from a paired $t$ test indicate statistical significance. An asterisk indicates significant differences between DAT-ineligible patients and all DAT-eligible patients combined. DAT = Device-aided treatment; NMSS = Non-motor Symptom Scale; NS = Not significant; PDQ-8 = Parkinson's disease 8-item questionnaire; SD = Standard deviation; UPDRS = Unified Parkinson's Disease Rating Scale 
represent an epidemiological prevalence in the PD patient population as judgment is likely biased by patient selection from only movement disorder centers that tend to treat more advanced-stage PD patients. Patients who were characterized as having APD had worse motor and NMS severity and reduced QoL compared with non-APD patients. This is consistent with findings from other studies showing disease characteristics [12] and motor and non-motor features in APD [13]. Both groups were similar regarding age, sex, and living situation, but differed in terms of caregiver support status, which is likely an effect of having APD.

Delphi criteria have been previously used by other investigators to define APD. The CEPA study [14] categorized APD symptoms by definitive symptoms, probable symptoms, and possible symptoms. The authors' list of symptom coverage is extensive and generally covered by our targeted Delphi criteria, which allows a more structured and simplistic method of assessment. Longer time since diagnosis, dyskinesia duration, and limitations of ADL are reported to be predictors for the diagnosis of APD [6]. That $87.0 \%$ of APD (versus $23.2 \%$ in non-APD) patients were reported as having motor fluctuations may hint that physician's judgment was strongly based on motor fluctuations. Compared with Delphi criteria for APD, which subsumes a broader range of symptoms under the diagnosis of APD, physician's judgment, based primarily on motor fluctuations, is too narrow.

Of APD patients, $66 \%$ were considered eligible for DAT. Within this group, many patients had ongoing DAT or had made the decision to initiate DAT. However, almost one-third of DAT-eligible patients did not plan on initiating DAT at the time of their study visit, demonstrating that patients did not elect to follow their clinician's suggested optimal treatment plan. Most DAT-eligible patients were not currently using DAT based on personal decision (outright refusal or the need for more time to decide). Transitioning from oral drug administration to more invasive measures is an important step for patients; therefore, it is not surprising that many patients initially decline to move forward with DAT or request more time to discuss and educate themselves prior to initiating the change in treatment. The large percentage of patients delaying their DAT initiation suggests a need for enhanced patient-physician guidance on navigating the transition to DAT for optimal patient outcomes, while still incorporating patient preferences $[15,16]$.

Further evaluations compared patient clinical outcomes as they related to DAT eligibility status. Generally, DAT-eligible patients had worse motor symptoms and QoL than did DAT-ineligible patients. Patients who were currently receiving DAT at the time of the study had significantly lower impairment in ADL, motor function, dyskinesia duration and disability, "Off" time, and lower NMSS total scores than did patients who were not currently on DAT (whether or not they were planning to initiate DAT). These findings are similar to other studies that demonstrated DAT improvement of motor and non-motor complications associated with APD [17, 18]. The fact that the Delphi criteria include two items on NMS (nighttime sleep and non-motor fluctuations) may make it more suitable to obtain a comprehensive patient profile to determine advanced PD or DAT eligibility. Evidence from the GLORIA registry, which sampled the largest cohort of advanced PD patients treated with LCIG in routine clinical care, showed NMS improvements in patients treated with DAT (i.e. LCIG) in multiple NMSS domains $[19,20]$. These findings further demonstrate that non-motor features of APD can be improved with optimized dopaminergic delivery. Of note, not all APD patients are candidates for DAT (eg, patients with dementia) and some non-APD patients may still be candidates for DAT because they have demanding functional needs (eg, young working individuals), they may be using DAT for the (non-approved) treatment of non-motor symptoms or for treatment of PD-related tremor, or they may have poor tolerability of oral levodopa. However, the reasons for non-APD use of DAT were not captured in the study and therefore remain speculative.

Patient baseline characteristics are in keeping with clinical reports in which DATs are implemented. Weaver and colleagues [18] report patient characteristics for 121 $\mathrm{dB}$ candidates with $\mathrm{APD}$, showing similar age and living situation but fewer patients with caregiver support compared with patients in the current study. Patients in the current study who were receiving DBS have similar scores as noted in the DAT-eligible group in UPDRS II assessments but scored lower in motor function as determined by UPDRS III compared with that reported by Weaver et al. [18]. A report from Garcia Ruiz and colleagues [17] summarizes patient characteristics from 20 open-label studies using CSAI in patients with APD. DAT-eligible patients from the current study showed similar duration of disease but lower mean age compared with all CSAI studies. Patients treated with LCIG also demonstrated similar age of DAT onset, duration of disease, and gender ratio [21].

This study utilized practicing clinicians and a large sample size of patients from multiple countries who were currently seeking medical support. It is important to note that the study was not designed to be an epidemiological study and the goal was not specifically to determine the percentage of APD patients (prevalence) using that methodology. The collected data demonstrate real-world evidence of treatment patterns and highlight gaps in current clinical care and possible areas for improvement. A study limitation and bias were noted 
regarding recruitment of inpatients at movement disorder clinics, possibly resulting in increased prevalence of (hospitalized) patients with more advanced PD. Clinical sites were chosen based on, among other aspects, availability of DAT. This likely contributed to the disproportionate representation of DAT modalities (i.e. more patients using LCIG). A bias may have occurred when the investigators were trained for the study where the investigators were informed about the Delphi criteria, set up by their peer movement disorder specialists, which may potentially have influenced their understanding and judgment. Another limitation to the study is the post hoc nature of the analysis regarding DAT eligibility. In addition, study results were only obtained from a single, independent patient visit. Without follow-up, it is unknown if DAT-eligible patients who were not currently using DAT have changed their minds and chose DAT or if DAT-ineligible patients have had a change in their DAT eligibility after this study concluded.

The present study reports findings from a cross-sectional, international, observational study of patients with PD. This study highlights the inconsistency in physician judgment for DAT eligibility and the actual number of patients considering it. The observed heterogeneity in patient identification results in increased numbers of patients with a delayed diagnosis of APD and, therefore, higher numbers of patients who do not receive optimized medical treatment.

\section{Conclusions}

There is a need for consistent criteria by which APD can be detected earlier, thereby allowing patients to adequately prepare for changing medical needs that arise in advancing stages of the disease. The Delphi criteria highlight some key criteria that are both quantifiable and tangible for the patient and the physician. These criteria will help to increase the awareness for these symptoms and further emphasize the need to screen these symptoms. Improving treatment for this patient population begins with the optimization of oral dopamine replacement therapies, which is dependent on the correct diagnosis of the disease stage and medication requirement. Altogether, these findings aid in further categorization of patients into APD and suggest the Delphi criteria for APD may be a useful assessment tool to aid patient classification and demonstrate the benefit of DAT in APD patients. Further studies are needed to validate and evaluate the use of these criteria in routine clinical practice.

\section{Additional file}

Additional file 1 Table S1. Types of current Parkinson's disease treatment. Table S2. Sensitivity analysis of correlations between physician's judgment of APD and individual Delphi criteria for APD (ongoing DAT patients excluded). Table S3. Association between physician's judgment of APD and individual prognostic parameters. (PDF 57 kb)

\section{Abbreviations}

ADL: Activities of daily living; APD: Advanced Parkinson's disease; CSAl: Continuous subcutaneous apomorphine infusion; DBS: Deep brain stimulation; LCIG: Levodopa-carbidopa intestinal gel; NMS: Non-motor symptoms; NMSS: Non-motor Symptom Scale; PD: Parkinson's disease; PDQ8: 8-item Parkinson's Disease Quality of Life Questionnaire; QoL: Quality of life; UPDRS: Unified Parkinson's Disease Rating Scale

\section{Acknowledgements}

We thank Stephanie Tedford, PhD, and Kelly M Cameron, PhD, ISMPP CMPP'M, of JB Ashtin who, on behalf of the authors, developed the first draft of the manuscript based on an author-approved outline and assisted in implementing author revisions throughout the editorial process; this medical writing support was funded by AbbVie, Inc. The authors thank the patients who participated in this observational study and all study investigators for their contributions.

\section{Funding}

This study was supported by AbbVie, Inc., North Chicago, IL. AbbVie designed the study and collected, analyzed, and interpreted the data. Medical writing support was also funded by AbbVie.

\section{Availability of data and materials}

AbbVie is committed to responsible data sharing regarding the clinical trials we sponsor. Access is provided to anonymized, patient and trial-level data (analysis data sets), as well as other information (e.g. protocols and clinical study reports) from AbbVie-sponsored Phase II-IV global interventional clinical trials conducted in patients (completed as of May 2004, for products and indications approved in either the United States or the European Union), as long as the trials are not part of an ongoing or planned regulatory submission). This includes requests for clinical trial data for unlicensed products and indications.

Access to this clinical trial data can be requested by any qualified researchers who engage in rigorous, independent scientific research, and will be provided following review and approval of a research proposal and statistical analysis plan (SAP) and execution of a data sharing agreement (DSA). Data requests can be submitted at any time and the data will be accessible for 12 months, with possible extensions considered. For more information on the process, or to submit a request, visit the following link: https://www. abbvie.com/our-science/clinical-trials/clinical-trials-data-and-informationsharing/data-and-information-sharing-with-qualified-researchers.html.

\section{Authors' contributions}

$A F, V S C F, L L, B E, I G S, K S, A T, K O, J C P, L B, K S, Y J$, and ZP were involved with conception, organization, and/or execution of the study. KO, JCP, LB participated in statistical analysis design and execution. All authors read, critiqued, and approved the final manuscript.

\section{Ethics approval and consent to participate}

To be included in the study, patients had to sign an authorization form to disclose personal health information and provided written informed consent. The study was approved by local ethics committees and performed according to the International Conference on Harmonization and Good Clinical Practice requirements, in accord with the principles of the Declaration of Helsinki. The local ethics committees that provided approval included those in Austria (Ethik Kommission des Landes Oberösterreich, Ethikkommission der Medizinischen Universität Innsbruck, Ethik Kommission des Bundeslandes Niederösterreichs), in Belgium (Universitair Ziekenhuis Antwerpen), in Canada (REB of Centre intégré de santé et de services sociaux de Chaudière-Appalach [MSSS pour les centres du Québec], Health Research Ethics Boards [UofA], Western University Health Science REB [HSREB], MSSS [authorized by MUHC], Ottawa Health Science Network REB, Conjoint Health Research Ethics Board of the University of Calgary, Queen's University Health Sciences \& Affiliated teaching hospitals REB [HSREB], University Health Network REB, IRB Services [Advarra], REB Horizon Health Network, MSSS [authorized by JGH], IRB Services [Advarra]), in Switzerland (Ethikkommission 
Ostschweiz Kantonsspital), in Germany (Ethikkommission der Universität zu Köln, Ethikkommission der Landesärztekammer Brandenburg,

Ethikkommission Ärztekammer Niedersachsen, Ethikkommission der Ländesärztekammer Thüringen, Ethik-Kommission Landesärztekammer Baden-Württemberg, Ethik-Kommission Albert-Ludwigs-Universität Freiburg, Ethik-Kommission der Ärztekammer Berlin, Ethikkommission Ärztekammer Nordrhein, Ethik-Kommission der Bayerischen Landesärztekammer, Ethikkommission der Ärztekammer Hamburg, Ethikkommission Ärztekamer Niedersachsen, Ethik-Kommission Rheinische Friedrich-Wilhelms-Universität Medizinische Fakultät, Ethikkommission Ärztekammer Sachsen-Anhalt, Ethikkommission Ärztekammer Niedersachsen, Ethikkommission Ärztekammer Nordrhein), in Greece (Ethics Committee of General Hospital of Thessaloniki "G. Papanikolaou", Ethics Committee of General Hospital of Thessaloniki "Papageorgiou", Ethics Committee of 251 Airforce General Hospital, Ethics Committee of Naval Hospital of Athens, Ethics Committee of University General Hospital "Attikon", Ethics Committee of University General Hospital of Heraklion, Ethics Committee of University General Hospital of Patras, Ethics Committee of Mediterraneo Hospital, Ethics Committee of University General Hospital of Alexandroupoli, Ethics Committee of HYGEIA Hospital, Ethics Committee of General Hospital of Athens "G. Gennimatas", Ethics Commmittee of University General Hospital of Thessaloniki "Axepa", Ethics Committee of University General Hospital of Ioannina, Ethics Committee of 417 Nursing Institution of Participial Army Fund [NIMTS]), in Ireland (Education and Research Committee St Vincent's University Hospital, Joint Research Ethics Committee SJH/AMNCH, Clinical Research Ethics Committee of the Cork Teaching Hospitals, Galway research ethics committee), in Israel (E. Wolfson Medical Center Helsinki Committee, IRB Committee Sheba Medical Center Israel, Tel Aviv Sourasky Medical Center Institutional Review Board, Ethics committee of Rabin Medical Center), in Italy (Comitato Etico delle Aziende Sanitarie dell'Umbria di Perugia, Comitato Etico Regional [CER] delle Marche c/o AUO Ospedali Riuniti, Comitato Etico AOU di Cagliari, Comitato Etico Indipendente Azienda Ospedaliero Universitaria Policlinico Consorziale di Bari, Comitato Etico Interaziendale AOU Città della Salute e della Scienza di Torino AO Ordine Mauriziano - ASL TO1, Comitato Etico Interaziendale della Provincia di Messina AOU Policlinico "G Martino", Comitato Etico Area Vasta Centro c/o AOU Careggi, Comitato Etico Indipendente dell'Azienda Ospedaliera Universitaria Policlinico Tor Vergata di Roma, Comitato Etico Seconda Università degli Studi di Napoli Azienda Ospedaliera Universitaria SUN-AORN "Ospedali dei Colli"), in Turkey (Kocaeli University Medical Faculty Ethics Committee), in the Czech Republic (Ethics Committee of the General Hospital of Charles University in Prague, Ethics Committee of the St Anna Hospital of Masaryk University in Brno), in Slovakia (the local legislation valid at that time of 2015 did not impose an obligation to approve epidemiological observational studies by the ethics committee; therefore, the opinions of the two ethics committees in the Czech Republic can be used to comply with the ethical principles in both countries), in Russia (Advisory council on ethics St Petersburg state budgetary healthcare institution city hospital No 40, Ethics committee of the federal state budgetary institution state research center, Independent Interdisciplinary Committee for Ethical Review of Clinical Studies [125468, Moscow, Leningradskiy prospect 51]), in Romania (National Commission of Bioethics [Comisia Nationala de Bioetica a Medicamentului si a Dispozitivelor Medicale]), in Hungary (Ethics committees of the Medical Research Council of Hungary [ETT] Egészségügyi Tudományos Tanács Klinikai Farmakológiai Etikai Bizottsága), in Slovenia (Republic of Slovenia Medical Ethics Committee, Institute of Clinical Neurophysiology, University Medical Centre Ljubljana [Komisija Republike Slovenije Za Medicinsko Etiko]), in Croatia (Drug Committee of Clinical Hospital Center Zagreb [Povjerenstvo za lijekove Kliničkog Bolničkog Centra Zagreb], Drug Committee of Clinical Hospital Center Osijek [Povjerenstvo za lijekove Kliničkog Bolničkog Centra Osijek], Drug Committee of Clinical Hospital Center Split [Povjerenstvo za lijekove Kliničkog Bolničkog Centra Split]), and Australia (Belberry Human Research Ethics Committee, Royal Brisbane and Women's hospital human research ethics committee).

\section{Consent for publication}

Not applicable.

\section{Competing interests}

The authors report no direct conflict of interest related to the work on this manuscript. Full financial disclosure is provided as follows. A Fasano was a study investigator and has served as an advisor for AbbVie, Inc.; consultant for UCB pharma, Medtronic, Boston Scientific, Ipsen, Sunovion, and AbbVie,
Inc. He has received research support from Medtronic, Boston Scientific, University of Toronto, Michael J. Fox Foundation for Parkinson's Research, and honoraria from UCB pharma, Medtronic, Novartis, Chiesi, Boston Scientific, AbbVie, Inc., Ipsen, Sunovion, and Teva for serving as a speaker. VSC Fung receives a salary from NSW Health. He has received unrestricted research grants from AbbVie and Merz, is on advisory boards and/or has received travel grants from AbbVie, Allergan, Cavion, Ipsen, Merz, Praxis, Seqirus, Stada, Teva, and UCB, and receives royalties from Health Press Ltd. L Lopiano was a study investigator and received research support from University of Turin and honoraria and travel grants for serving as a consultant and speaker for AbbVie, Inc., UCB, and Zambon. B Elibol was a study investigator and has served as a local advisor for AbbVie, Inc. and has received honoraria from AbbVie, Inc. for serving as a speaker. IG Smolentseva was a study investigator. K Seppi has received consultancy fees from Teva, UCB, Lundbeck, AOP Orphan Pharmaceuticals AG, Roche, Grunenthal, and AbbVie. He has also received honoraria from the International Parkinson and Movement Disorders Society, research grants from FWF Austrian Science Fund, Michael J Fox Foundation, and the International Parkinson and Movement Disorder Society, outside the submitted work. A Takáts was a study investigator and has served as an advisor for AbbVie, Inc. She has also served as a consultant for UCB pharma, Ever pharma, TEVA, and AbbVie, Inc., and has received honoraria from UCB, MERZ, AbbVie, Inc., and Teva for serving as speaker. Z Pirtosek was a study investigator and has received compensation from AbbVie, Inc., for speaker-related activities. K Onuk, JC Parra, L Bergmann, K Sail, and Y Jalundhwala are employees of AbbVie, Inc., and may hold corporate stock or stock options.

\section{Publisher's Note}

Springer Nature remains neutral with regard to jurisdictional claims in published maps and institutional affiliations.

\section{Author details}

${ }^{1}$ Edmond J. Safra Program in Parkinson's Disease and Morton and Gloria Shulman Movement Disorders Clinic, Toronto Western Hospital and Division of Neurology, UHN, Division of Neurology, University of Toronto, 399 Bathurst St, 7McL412, Toronto, ON M5T 2S8, Canada. ${ }^{2}$ Krembil Research Institute, 399 Bathurst St, Toronto, Ontario M5T 2S8, Canada. ${ }^{3}$ Movement Disorders Unit, Department of Neurology, Westmead Hospital, Cnr Hawkesbury Road and Darcy Road, Westmead NSW 2145, Australia. ${ }^{4}$ Sydney Medical School, University of Sydney, Edward Ford Building A27, Sydney, Australia. ${ }^{5}$ Department of Neuroscience, University of Turin, Via Cherasco 15, 10126 Turin, Italy. ${ }^{6}$ Department of Neurology, Hacettepe University Hospitals, Hacettepe Mh, 06239 Ankara, Turkey. ${ }^{7}$ Department of Neurology, Russian Postgraduate Medical Academy, 2-second Botkinsky travel, 5, 125284 Moscow, Russia. ${ }^{8}$ Department of Neurology, Medical University Innsbruck, Innrain 52, Christoph-Probst-Platz, 6020 Innsbruck, Austria. ${ }^{9}$ Neurological Clinic of Semmelweis University, Balassa J.u.6, Budapest H-1083, Hungary.

${ }^{10}$ AbbVie, Inc, 1400 Sheridan Road, North Chicago, IL 60064, USA.

${ }^{11}$ Department of Neurology, University Medical Center Ljubljana, Zaloška cesta 2, 1000 Ljubljana, Slovenia.

Received: 12 December 2018 Accepted: 20 March 2019 Published online: 02 April 2019

\section{References}

1. von Campenhausen S, Bornschein B, Wick R, Botzel K, Sampaio C, Poewe W, et al. Prevalence and incidence of Parkinson's disease in Europe. Eur Neuropsychopharmacol. 2005;15(4):473-90.

2. Goetz CG, Poewe W, Rascol O, Sampaio C, Stebbins GT, Counsell C, et al. Movement Disorder Society task force report on the Hoehn and Yahr staging scale: status and recommendations. Mov Disord. 2004;19(9):1020-8.

3. Schrag A, Quinn N. Dyskinesias and motor fluctuations in Parkinson's disease. A community-based study. Brain. 2000;123(Pt 11):2297-305.

4. Bach JP, Riedel O, Klotsche J, Spottke A, Dodel R, Wittchen HU. Impact of complications and comorbidities on treatment costs and health-related quality of life of patients with Parkinson's disease. J Neurol Sci. 2012;314(1-2): $41-7$.

5. Clarke CE, Worth P, Grosset D, Stewart D. Systematic review of apomorphine infusion, levodopa infusion and deep brain stimulation in advanced Parkinson's disease. Parkinsonism Relat Disord. 2009;15(10):728-41. 
6. Kulisevsky J, Luquin MR, Arbelo JM, Burguera JA, Carrillo F, Castro A, et al. Advanced Parkinson's disease: clinical characteristics and treatment (part 1). Neurologia. 2013;28(8):503-21.

7. Benito-Leon J, Bermejo-Pareja F, Morales-Gonzalez JM, Porta-Etessam J, Trincado R, Vega S, et al. Incidence of Parkinson disease and parkinsonism in three elderly populations of Central Spain. Neurology. 2004;62(5):734-41.

8. Hely MA, Morris JG, Traficante R, Reid WG, O'Sullivan DJ, Williamson PM. The Sydney multicentre study of Parkinson's disease: progression and mortality at 10 years. J Neurol Neurosurg Psychiatry. 1999;67(3):300-7.

9. Muangpaisan W, Mathews A, Hori H, Seidel D. A systematic review of the worldwide prevalence and incidence of Parkinson's disease. J Med Assoc Thail. 2011;94(6):749-55.

10. Antonini A, Stoessl AJ, Kleinman LS, Skalicky AM, Marshall TS, Sail KR, et al. Developing consensus among movement disorder specialists on clinical indicators for identification and management of advanced Parkinson's disease: a multi-country Delphi-panel approach. Curr Med Res Opin. 2018; 34(12):2063-73.

11. Barone P, Antonini A, Colosimo C, Marconi R, Morgante L, Avarello TP, et al. The PRIAMO study: a multicenter assessment of nonmotor symptoms and their impact on quality of life in Parkinson's disease. Mov Disord. 2009; 24(11):1641-9.

12. Hassan A, Wu SS, Schmidt P, Malaty IA, Dai YF, Miyasaki JM, et al. What are the issues facing Parkinson's disease patients at ten years of disease and beyond? Data from the NPF-QII study. Parkinsonism Relat Disord. 2012; 18(Suppl 3):S10-4.

13. Kruger R, Klucken J, Weiss D, Tonges L, Kolber $P$, Unterecker $S$, et al. Classification of advanced stages of Parkinson's disease: translation into stratified treatments. J Neural Transm (Vienna). 2017;124(8):1015-27.

14. Luquin MR, Kulisevsky J, Martinez-Martin P, Mir P, Tolosa ES. Consensus on the definition of advanced Parkinson's disease: a neurologists-based Delphi study (CEPA study). Parkinsons Dis. 2017;2017:4047392.

15. Marshall T, Pugh A, Fairchild A, Hass S. Patient preferences for device-aided treatments indicated for advanced Parkinson disease. Value Health. 2017; 20(10):1383-93.

16. Odin P, Ray Chaudhuri K, Slevin JT, Volkmann J, Dietrichs E, Martinez-Martin $P$, et al. Collective physician perspectives on non-oral medication approaches for the management of clinically relevant unresolved issues in Parkinson's disease: consensus from an international survey and discussion program. Parkinsonism Relat Disord. 2015;21(10):1133-44.

17. Garcia Ruiz PJ, Sesar Ignacio A, Ares Pensado B, Castro Garcia A, Alonso Frech F, Alvarez Lopez $\mathrm{M}$, et al. Efficacy of long-term continuous subcutaneous apomorphine infusion in advanced Parkinson's disease with motor fluctuations: a multicenter study. Mov Disord. 2008;23(8):1130-6.

18. Weaver FM, Follett K, Stern M, Hur K, Harris C, Marks WJ Jr, et al. Bilateral deep brain stimulation vs best medical therapy for patients with advanced Parkinson disease: a randomized controlled trial. JAMA. 2009:301(1):63-73.

19. Antonini A, Poewe W, Chaudhuri KR, Jech R, Pickut B, Pirtosek Z, et al. Levodopa-carbidopa intestinal gel in advanced Parkinson's: final results of the GLORIA registry. Parkinsonism Relat Disord. 2017;45:13-20.

20. Antonini A, Yegin A, Preda C, Bergmann L, Poewe W, Investigators Gs, et al. Global long-term study on motor and non-motor symptoms and safety of levodopa-carbidopa intestinal gel in routine care of advanced Parkinson's disease patients; 12-month interim outcomes. Parkinsonism Relat Disord. 2015;21(3):231-5.

21. Bajenaru O, Ene A, Popescu BO, Szasz JA, Sabau M, Muresan DF, et al. The effect of levodopa-carbidopa intestinal gel infusion long-term therapy on motor complications in advanced Parkinson's disease: a multicenter Romanian experience. J Neural Transm (Vienna). 2016;123(4):407-14.

\section{Ready to submit your research? Choose BMC and benefit from:}

- fast, convenient online submission

- thorough peer review by experienced researchers in your field

- rapid publication on acceptance

- support for research data, including large and complex data types

- gold Open Access which fosters wider collaboration and increased citations

- maximum visibility for your research: over $100 \mathrm{M}$ website views per year

At BMC, research is always in progress.

Learn more biomedcentral.com/submissions 